\title{
Service Quality and Passengers' Satisfaction in the Railway Transportation Service: A Case of Addis Ababa Light Rail Transit (AA-LRT)
}

\author{
Birhanu Bekele Kumsa \\ Lecturer, College of Business and Economics, Department of Management, Dilla University, P.O.Box: 419, \\ Dilla, Ethiopia
}

\begin{abstract}
The main objective of this research is to evaluate the current status of service quality and passengers satisfaction of light rail transit service in Addis Ababa from the point of view of passengers' expectations of the service quality and perceptions of the service delivered by AA-LRT. To achieve this objective, descriptive research design were used to analyze the data collected through questionnaire survey from a sample of 384 passengers of the two routes. These respondents were selected using convenient--judgmental sampling method and stations were selected using simple random sampling methods. The data collected through the questionnaire were analyzed using statistical tools such as mean, standard deviation, gap analysis and spearman's correlation analysis with the help of SPSS v. 24 by applying modified SERVQUAL instrument for the railway service, RAILQUAL comparisons between passengers' expectations and perceptions of service were undertaken. The major finding of the study indicates, AA-LRT passengers' perceptions of service quality delivered were lower than their expectations, the highest gaps were given by AA-LRT passengers towards the comfort, reliability, assurance and empathy attributes, whereas lowest gaps were given to tangibility and responsiveness and the overall passengers satisfaction levels towards the service delivered was slightly not satisfactory. The finding also reveals that positive and significant relationship between service quality dimensions and customer satisfaction. Based on the findings of the study, the researcher recommended that AA-LRT needs to improve quality of services in all dimensions so as to satisfy customer's needs and should focus to top rated attributes with their gaps size; frequency and punctuality of train, availability of shelters and seats at stations, individual attentions to pregnant women, children, old and handicapped peoples, suffocation due to overload and more stand passengers in train, informing passengers whenever there are delays, safety and security of passengers both at stations and on the train and ticketing system.
\end{abstract}

Keywords: Service quality, Service quality dimension, SERVQUAL, RAILQUAL, Customer Expectation, Customer Perception, Customer Satisfaction.

DOI: $10.7176 / \mathrm{JMCR} / 74-01$

Publication date: December $31^{\text {st }} 2020$

\section{Introduction}

Mobility is one of the most fundamental and important characteristics of economic activity as it satisfies the basic need of going from one location to the other, a need shared by passengers, freight and information. The transport sector is thus becoming important component of the economy impacting on development and the welfare of populations (Hundal, 2015). When transport systems are efficient, they provide economic and social opportunities and benefits that result in positive multipliers effects such as better accessibility to markets, employment and additional investments (Agrawal, 2008). The railway transport industry is one of the world's most important service industries. It is essential to economic progress. This will achieved only if there is quality service in relative with the expectation of customers. In an increasingly global community and market place, railway transports makes possible the rapid movement of millions of peoples and huge freight. The end product of railways is the transportation services it offers to its customers. And the main performance indicator of a railway is its service quality. By service quality is intended all the sequence of behavior that must take place efficiently and effectively to transport the passenger from place to place. Due to the growing importance of quality in our life, customers desire to enjoy a relatively superior quality services have been increased. It is especially very critical in a highly growing environment such as that of the Ethiopian railway operating environment. Therefore, service quality improvement is key issue that determines the very survival of the railways itself and improving the economic and social development of the country.

According to Marinov, Agajere, Bigotte, Proietti, Gerenska, (2014) Light rail has brought new advantages to city mobility. The decision-making process and choice between transportation systems is not only in technology but also in the type of services attributes (speed, reliability, comfort, convenience, safety, special services, modern ticketing system, safety of luggage and punctuality of train, professional employees)its image and impact. The Light Rail transit, besides being financially beneficial comparing to many other systems, also reduces commuting cost especially when living farther from the city center. Additionally, it reduces traffic congestion and restructures mobility around cities, generating urban development in city centers and in suburban. 
Even if it is growing, there is no evidence that bear out the above provisions in the case of an Ethiopian railway context particularly in Addis Ababa light rail transit. Then, the evaluation of service quality and level of customers' satisfaction provides an important feedback for the corporation, government and responsible peoples to evaluate and improve the service to the passengers. Any service improvement programs that do not take passengers' attitude on the quality of service the rail system offered and delivered into consideration will not achieve its objectives.

This study attempts to apply the service quality measurement instrument (SERVQUAL) modified for the railway service context (RAILQUAL) in evaluating service quality gaps and passengers satisfaction level and show the relationship of these gaps in determining the overall passengers' satisfaction in Addis Ababa light rail transit.

\subsection{Statement of the Problem}

The need to increase mobility of passengers in Addis Ababa municipality and the emergence of transport sustainability led to the development of a light railway system in the city. It was expected that Addis Ababa light real system delivers quality service, reduce the transportation problem grounded for long years and the overflow of passengers in the city. It was about improving the communities life by making Addis Ababa an even better place to live and work in. It was about encouraging rapid economic development, industrialization and international competitiveness with efficient, high quality and modern transport infrastructure. The government intended with such project to encourage the downtown citizen and creating conducive transport system to the city.

Currently, much is not known on the service delivery system of the light rail transit as the passengers' needs and wants are growing in variety. In such an in instance, AA-LRT need to be aware of the newest shift and trend to be able to respond to customer demands on time. Precise and timely information on a wide range of customer needs and expectations become critically important in that way. Thus, the main issue is to evaluate the current status of the service quality and customer satisfaction in the AA-LRT services and whether there is any discrepancy between the expectations and perceptions of commuters towards the service provided. Some studies has been done from different perspective of the railways service specially from the technical construct measures of the rail system in Ethiopia. Accordingly, Fasil, (2014) from Engineering in Railway Study conducted research on 'Service Quality Indicator for Ethiopian Freight Railways'. Similarly, improving traffic safety at railroad level crossings "Pedestrian Level Crossing Safety on the East-West Line of AA-LRT"(Haptamu, 2015); Effective railway time table generation in Ethiopia (Tekle,2014); the actual safe movement of passengers and freight through implementation of signaling and train control systems in AA-LRT (Tebebu, 2014) and assessment of the operation and stations facility of the light rail transit (Kefele, 2016). None of these studies focused on the evaluation of the service quality delivered and customer satisfaction level in AA-LRT. In fact the service year of AA-LRT was short and the result of all these studies mentioned above were pre-requisite for the operation of the system than evaluation of the service it delivered. After more than one service year, one study conducted on determinants of passengers' satisfaction in AA-LRT (Haileyesus, 2016) from psychology department. According to him further improvement need to be taken to improve the service and to increase the level of customer satisfaction.

At the present, there is no evidence that shows the current status of the service quality and passengers satisfaction in Ethiopian rail way context particularly AA-LRT. The situation calls for the need of studies to fill the gap. It is essential for the Railway Corporation in general and AA-LRT in particular and as well for responsible bodies of government to know about the opinion of the passengers regarding the services offered to them and their satisfaction level in order to make future policies, provisions, standard for quality service and improvement action decision. Hence, a research should be conducted to understand both the expectations and perceptions of customers and also measure them from their perspective in order to identify gaps in delivering service quality to ensure customer satisfaction.

\subsection{Objectives of the study}

The general objective of the study is to evaluate the current status of service quality and passengers satisfaction in AA-LRT. The study tries to reach the following specific objectives:

$>$ To determine passengers' expectations and perceptions of the service quality in AA-LRT.

$>$ To find out the gap between passengers' expectations and their perceptions of the service delivered by AA-LRT.

$>$ To determine the overall level of passengers' satisfaction with regard to AA-LRT service.

$>$ To examine the relationship between service quality dimensions and customer satisfaction.

\section{Materials and Methods}

Descriptive research design with quantitative approach was employed. This was because of its high degree of representativeness and the ease in which a researcher could obtain the participants' opinion (Polit \& Beck, 2004). Moreover, it is a well-known research design when the purpose of the study is to describe the characteristics of a 
certain group (Shukla, 2010). The survey of this study was conducted in the cross-sectional design whereby data and/or information were collected from the passengers of AA-LRT once in a time, on different stations.

The population of the study consists of all passengers of Addis Ababa light rail transit who use the light rail transport service of the two lines (east-west and north-south) through 39 stations. Data from ERC, in year 2016 depicts that there are a total of 38 stations currently working through the two lines. From the total number of 38 stations, 10 stations (Ayat, C.M.C, Meganagna, Hayahulet1, Stadium, Abnet, Minilik II Square, Riche, Nefas Silk 1 and Saris) five from each line were selected using random sampling method.

In this research the sample is passengers of Addis Ababa light rail transit. The fact that this research attracted to roughly homogeneous participants in their service use may determine the sample size. The sample size of this research is 384 passengers from unknown (infinite) population. The sample size of the study is determined by using the formula developed by Cochran (1963).

$n o=\frac{Z^{2} p q}{e^{2}} \quad$ (For infinite population)

no $=$ the sample size

Where:

$\mathrm{Z}^{2}=$ the abscissa of the normal curve that cuts off an area

$\mathrm{e}^{2}=$ the desired level of precision

$\mathrm{p}=$ the estimated proportion (standard deviation) of an attribute that is present in the population and $\mathrm{q}$ is $1-\mathrm{p}$, the value of $\mathrm{Z}$ is found in statistical tables which contain the area under the normal curve.

$$
n o=\frac{(1.96)^{2}(0.5)(0.5)}{(0.05)^{2}}=384.16 \approx 384
$$

The above sample size is the representative sample proportion at $95 \%$ confidence level and $\pm 5 \%$ precession when population is large and unknown (Cochran, 1963).

Moreover, Primary source of data was used to undertake the study. According to Biggam (2008) primary data is the information that the researcher finds out by him/herself regarding a specific topic. The main advantage with this type of data collection is that it is collected with the research purpose in mind. Therefore, the respondents' response through questionnaire was used as a primary data. The questionnaire was comprised of four parts; the first part of the questionnaire was the general backgrounds information that covers respondents' personal details and travel details. The second and the third part of the questions were the main parts of the questionnaire that comprises of 33 questions each aimed at finding the respondents' opinions pertaining to the expectations and perceptions of service quality in Addis Ababa light rail transit and the last part was about the overall customers' satisfaction. In the questions the researcher used 7-point Likert-scale where the respondents are asked to select the most appropriate number that correspondents to extent to which they agree with a statement. The scales in this survey questions is 1 to 7 with " 1 " denoting "strongly disagree" and " 7 " denoting "strongly agree".

The data collected from respondents have been analyzed by using descriptive statistics, gap analysis and nonparametric test (spearman's correlation analysis) with the help of SPSS version 24. Descriptive statistics was carried on to describe the frequency, percentage, mean and standard deviation of the response, whereas gap analysis was carried on to find out the service quality gaps. On the other hand spearman's correlation analysis was carried on to look at the relationship between service quality dimensions and customer satisfaction in AA-LRT.

\section{Results and Discussion}

The purpose of this analysis section is to investigate and describe the stated specific objectives through analysis of primary data collected from the survey. It focuses on significantly responding the research questions. This will make possible to arrive at the objectives of the study through describing and interpreting the practical trend with regard to service quality and passengers satisfaction in Addis Ababa light rail transit.

The data collected is mainly based on passengers' expectations and perceptions of the various items of the RAILQUAL in light of SERVQUAL model and the overall satisfaction level. In addition, some demographic data including travel information of the respondents are collected. A general description of the customers' expectations and perceptions of the various dimensions is done using descriptive statistics. In order to assess the actual service quality and the customer satisfaction towards it, a gap score analysis is also carried out based on the difference between the expectations and perceptions $(\mathrm{P}-\mathrm{E})$. Besides, the relationship between service quality dimensions and customer satisfaction were examined by applying non-parametric test (Spearman's correlation coefficient). 


\subsection{Questionnaire Response Rate}

Table 4.2 Response rate

\begin{tabular}{|c|c|c|c|}
\hline $\begin{array}{c}\text { Questionnaire } \\
\text { Distributed }\end{array}$ & Questionnaire Collected & Survey Eliminated & $\begin{array}{c}\text { Usable as percentage } \\
\text { of population }\end{array}$ \\
\hline 384 & $356(93 \%)$ & 36 & $320(83 \%)$ \\
\hline
\end{tabular}

Source: Own survey (2017)

During the period of study, a total of 384 questionnaires were distributed to passengers that use the service of Addis Ababa light rail transit. The above table 2,shows the response rate of the passengers, the total number of questionnaires returned was $356(93 \%)$ which was satisfactory compared to what has been expected. Of these only $320(83 \%)$ of the total sample are found to be usable. Being incomplete the remaining 36 are eliminated. However the total number of questionnaires cleaned was considered to be sufficient for data analysis.

\subsection{Background Information of the Respondents}

Passengers were classified according to their gender distribution, age distribution, educational level, income level, occupational status, frequency of travel, purpose of travel and length of travel. To present a descriptive statistics for this part bar and pie charts and cross tabulation were used. Bar and Pie charts were to present the individual information, while cross tabulation was used to present the variables and sample characteristics. The reason for this choice of presentations graphs was because the data were categorical by nature and bar and pie charts were the main graphical presentation tools for such nature of data. Moreover, the researcher used cross-tabulation to link the variables and the sampled population. The consequent figures below present the characteristics of sample with the listed variables.

\subsubsection{Gender Difference}

Figure 4.4.1Pie chart; Gender Distribution of Respondents
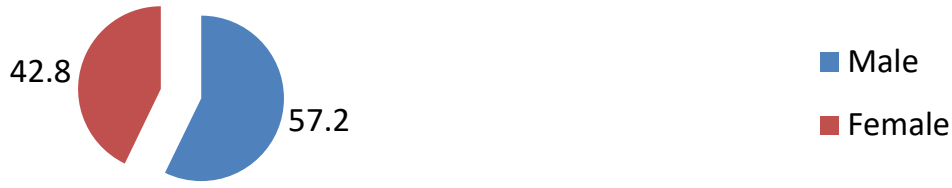

Source: own survey (2017)

Figure 4.4.1 shows the number of male passengers (57.2\%) was greater than female passengers (42.8\%). The proportion was somewhat deviated. However, this cannot lead to the conclusion of large number of passengers in AA-LRT are males, during the survey most of passengers were females and the majority of passengers who filled the questionnaire are males compared to females respondents' percentage, this is mainly due to lack of interest in female passengers to react to questionnaire surveys and the tendency of women expecting more than men and get in touch with the conclusion of nothing will done with providing information for such study to improve quality of service.

\subsubsection{Age Difference}

Figure-4.4.2: Age Distribution of Respondents

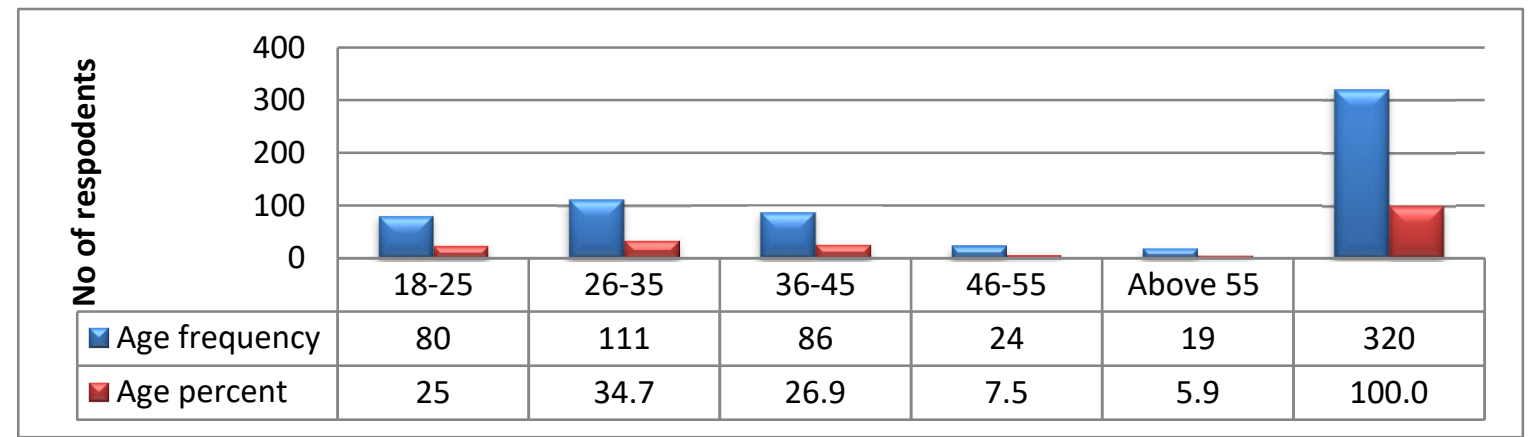

Source: own survey (2017)

As one can see from figure 4.4.2, most respondents were in the age categories $26-35(34.7 \%)$ or $36-45(26.9 \%)$ and $18-25(25 \%)$ respectively. The age group categories (46-55) took the second least place (7.5\%) next to elders age category $(5.9 \%)$ which is too small. From this age category, those age categories $26-35(34.7 \%)$ and almost relative numbers of the respondents $36-45(25 \%)$ and/or $26.9 \%$ have a large share in participation of questionnaire 
survey and believed as war mage category that enable them to answer the questionnaires in a manner which can reflect the current status of service quality in AA-LRT for having a improved quality service typically. Moreover, one can understand that customer of AA-LRT service are adult at large.

\subsubsection{Educational Background}

Figure 4.4.3: Educational Background of Respondents

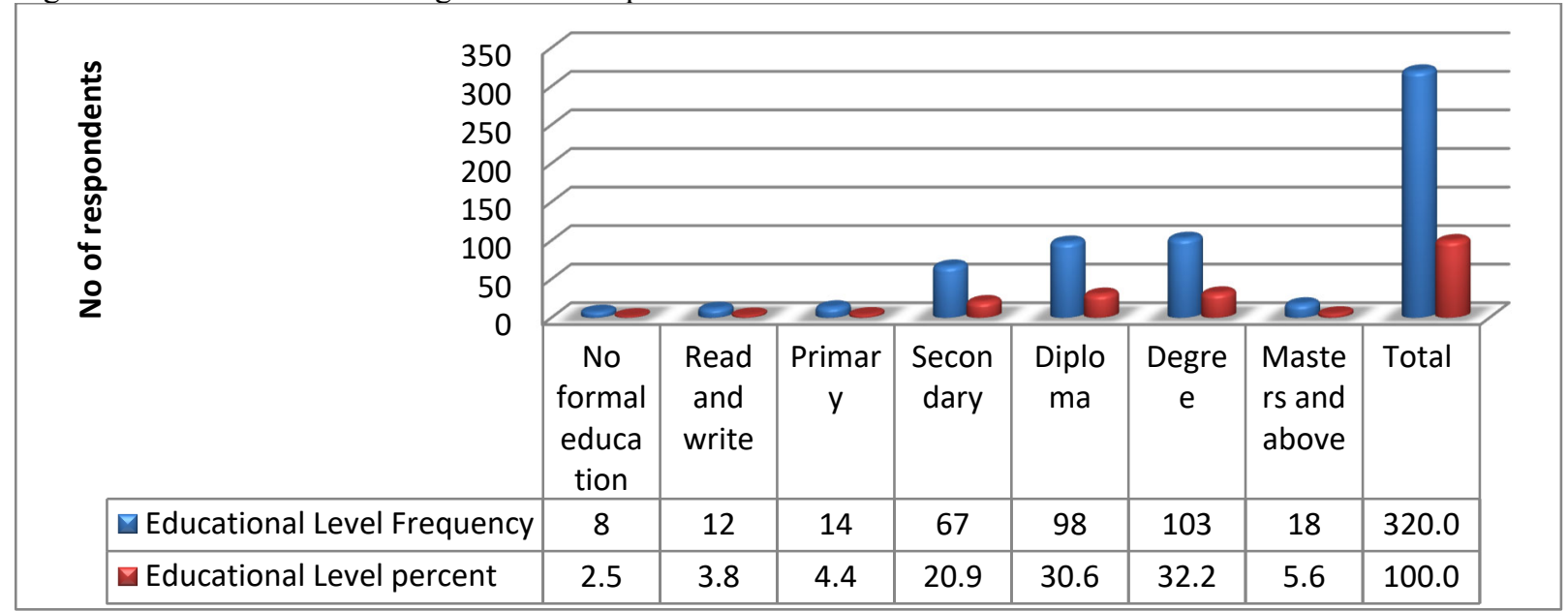

Source: own survey (2017)

The information in figure4.4.3 reveals that the dominant figure goes to those have degree (32.2\%), followed by diploma holders $(30.6 \%)$ and as well secondary school $(20.9 \%)$. Of the sample $2.5 \%$ and $3.8 \%$ are respondents those have no formal education and primary school respectively and have less share in participation of filling the survey. A few respondents (5.6\%) are those have masters degree and above and can be considered as better at measuring the actual status of AA-LRT. As it clearly indicated on figure 4.4 .3 above, the respondents have different educational levels, which imply that their expectation of service quality differs from person to person depending on his/her educational background. Moreover, it can be concluded that the respondents can understand the questions and can measure the service quality measuring parameters appropriately.

\subsubsection{Respondents by Occupation}

Figure 4.4.4: Occupational Status of Respondents

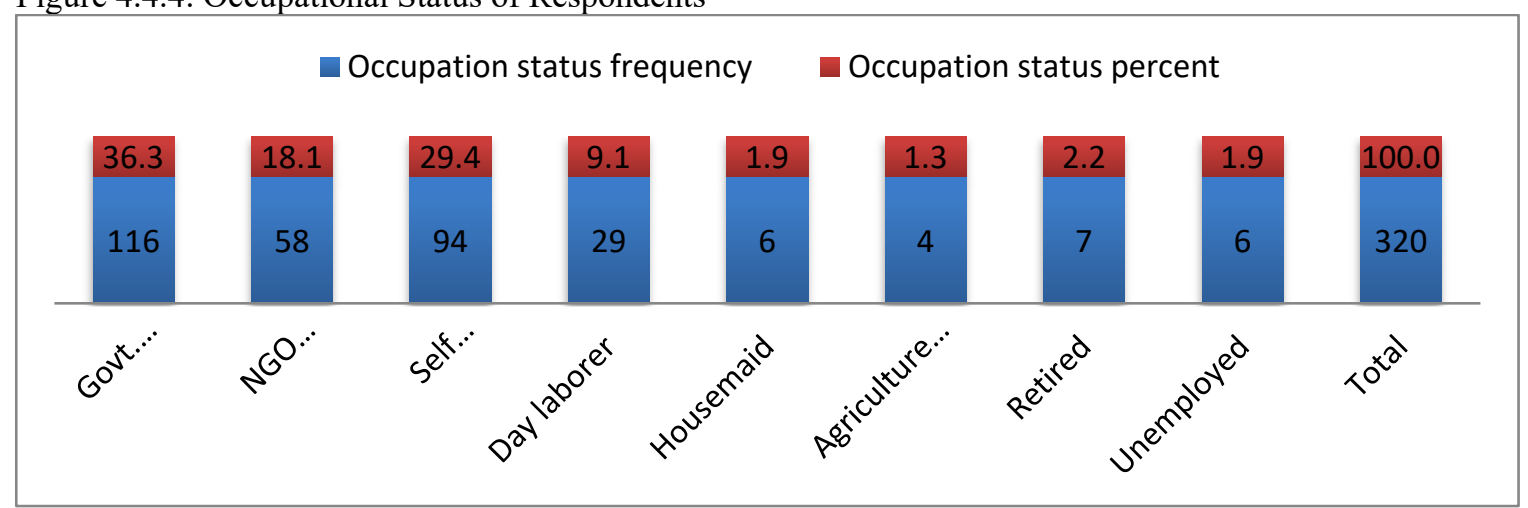

Source :own survey (2017)

The above data regarding occupational status was another background information of the respondents which was taken into consideration in this study. It is evident from the figure4.4.4 above that a significant proportion of the respondents $(36.3 \%)$ were government employee. The second large part of the respondents $(29.4 \%)$ were self employee, followed by $(18.1 \%)$ respondents were non-governmental workers. The figure also indicates $9.1 \%$ of the respondents were day laborers and other insignificant numbers of respondents $(1.9,1.3,2.2$ and 1.9) were housemaids, agriculture/farming, retired and unemployed respectively. Therefore, from this occupation data analysis one can observe that the majority of the passengers were civil servants followed by respondents who were engaged in their own business and NGO employee. The covert message of the data point out that the service of AA-LRT at pick hours (morning, mid-day and night is important to contribute to the work hours, since majority of the service commuters are civil servant at different organizations. 
i. Respondents' Income Level

ii. Figure-4.4.5:Income level of respondents

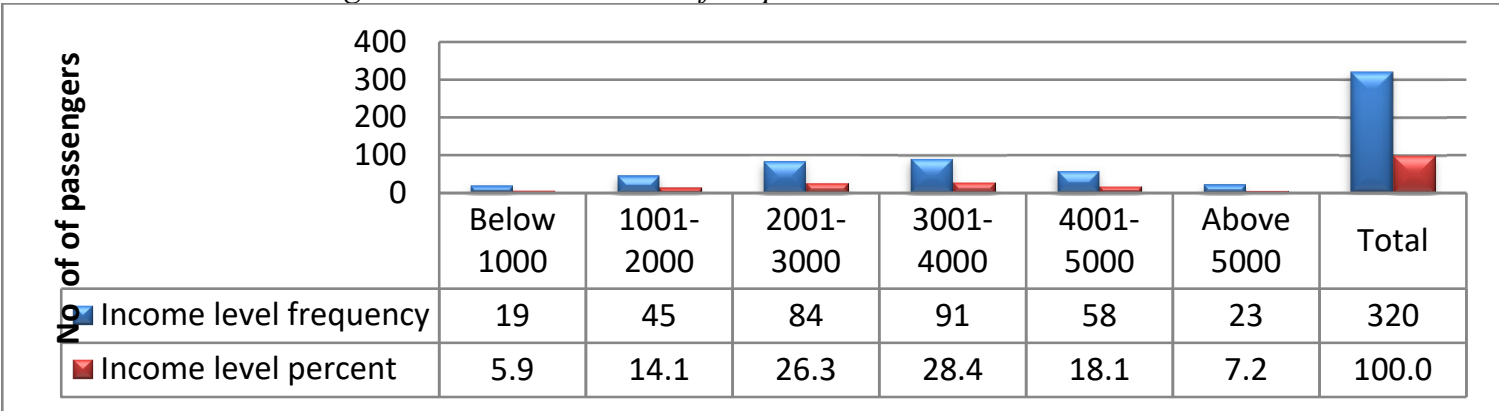

Source :own survey (2017)

The above figure 4.4.5 shows that the distribution of the passengers(respondents) in terms of their monthly income, the majority of the respondents $(28.4 \%)$ earn a monthly income of EBr. 3001-4000 and very closely (26.3\%) earn EBr.2001-3000. Nearly equal numbers of respondents (5.9\&7.2\%) earn below EBr. 1000 and above EBr.5001 respectively. In the same case, there were some respondents (18.1\%) who earn EBr. 4001-5000; the remaining 14.1\% respondents earn EBr.1001-2000.From the above data one can understand that the income of the samples of this study mostly depended on their occupation and educational qualification. As it discussed earlier (figure 4.4.3) the majority of the respondents (32.2\%) were found to have a qualification of first degree. Again from figure 4.4.4, it has been indicated that the majority of the respondents $(36.3 \%)$ were found to be civil servants. Based on this finding one can infer that the passengers who use AA-LRT are those who are at the middle level of monthly income category according to the result observed in this study.

\subsubsection{Respondents' Travel Frequency}

Figure 4.4.6:Respondents'highest frequency of travel

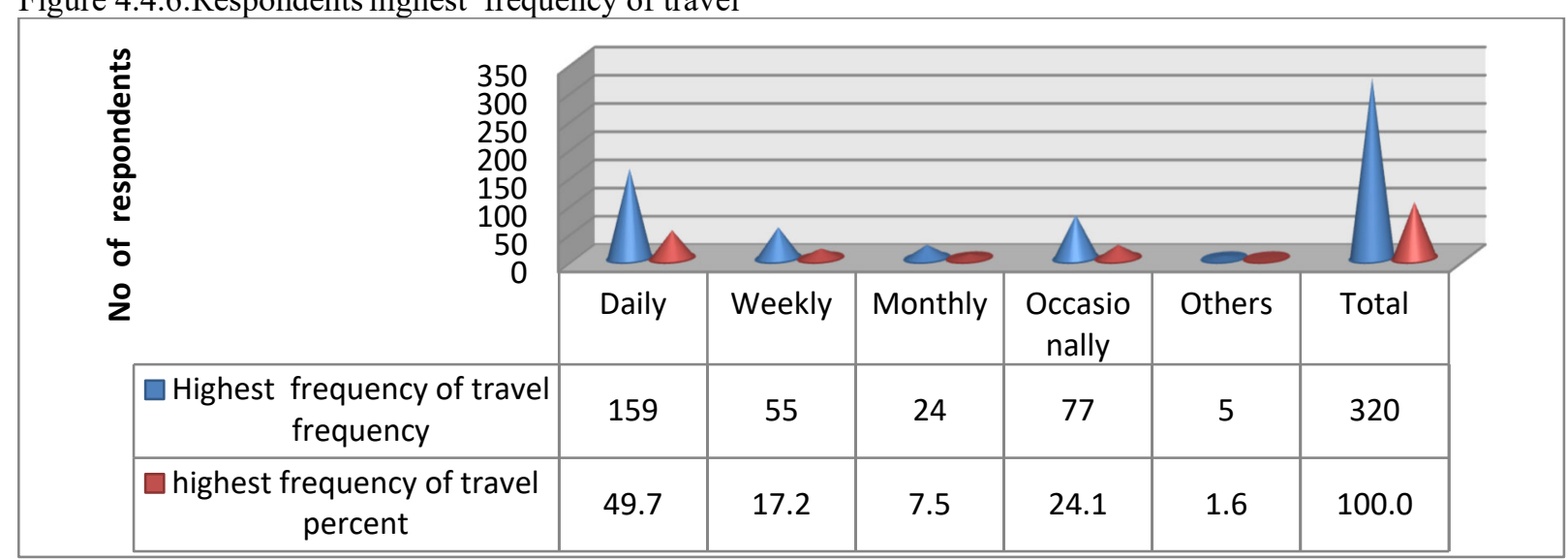

Source :own survey (2017)

From figure 4.4.6 above, we can see the other main variable that the respondents were asked, the frequency of travel that they make using AA-LRT service. The information is presented on the figure above. For this question the majority number of respondents $49.7 \%$ ) answered that they make a travel with the AA-LRT daily and followed by respondents $(24.1 \%$ and $17.2 \%)$ who travel occasionally and weekly respectively. In other words, as for their trip characteristics the participants were daily, occasionally and weekly riders. The other $7.5 \%$ of the respondents answered that they were monthly use the light rail to travel from place to place. Insignificant number of respondents $(1.6 \%)$ are use the Addis Ababa light rail transit service to others travel time. From the analysis of this data it is possible to say that a significant proportion, almost half percentages of the respondents were the daily passengers in AA-LRT service. Therefore, one can conclude as the AA-LRT service is used frequently by a large number of respondents as revealed from the sample taken in this study and shows that respondents are well experienced about the nature of service delivered in AA-LRT which enable them to measure it appropriately. 


\subsubsection{Purpose of Most Travel}

Figure 4.4.7:Respondents'purpose of most travel

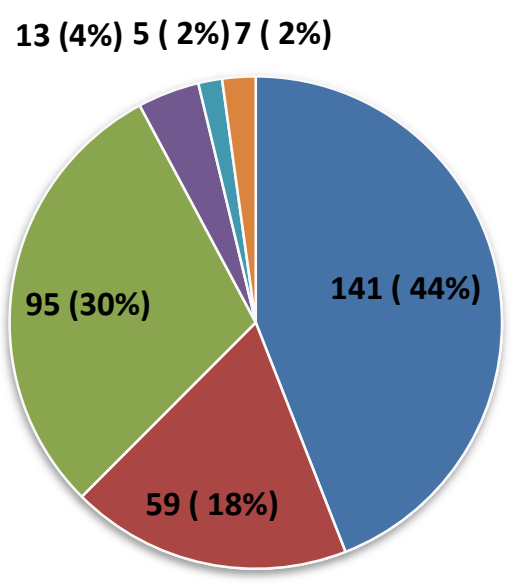

- Official/business

- Education

- Personal

- Vacation

- Sports

- Others

Source :own survey (2017)

The second main variable considered under travel details for this study was the purpose of travel. Accordingly, figure 4.4.7 shows that very significant number of respondents almost around near to half percent (44\%) were who used AA-LRT service for the purpose of official and/or business, followed by second large part of the respondents $(30 \%)$ used for the personal reason. This validate the result has been observed earlier in the occupational status analysis (Figure 4.4.4) that the majority of AA-LRT service users were government and/or self employee. The figure also indicates that $18 \%$ of the respondents were those used AA-LRT service for educational purpose. The other insignificant numbers of respondents $(4 \%, 2 \%, 2 \%)$ were those used the service for the purpose of vacation, sport and others respectively. From this travel purpose analysis, one can conclude that official and/or business purpose were the dominance purpose for what customers were used AA-LRT service. This conclusion expose further conclusion that regardless of its inconvenience, AA-LRT considered as the better transportations means for the work hours based on the response of the respondents.

\subsubsection{Distance of Travel}

Figure 4.4.8:Respondents' distance of travel per day

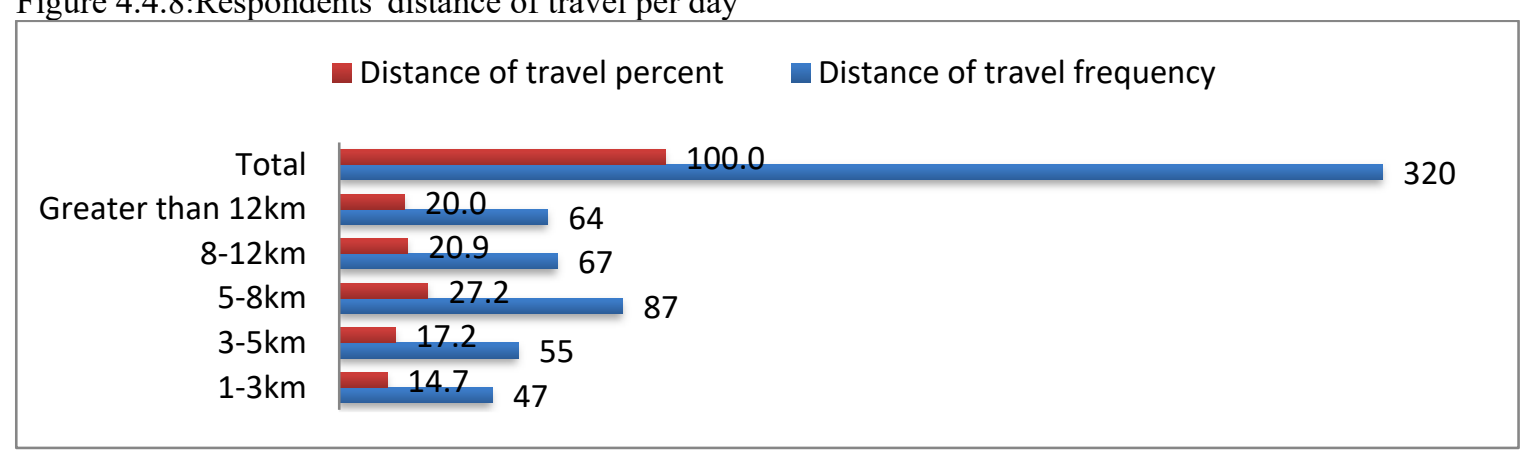

Source :own survey (2017)

Figure 4.4.8 above shows that the other critical variable considered again under travel details, distance of travel. The majority respondents $(27.2 \%)$ replied that they travel $5 \mathrm{~km}-8 \mathrm{~km}$ by using the AA-LRT service and almost the same numbers of respondents $(20.9 \%$ and $20 \%)$ who travel for $8 \mathrm{~km}-12 \mathrm{~km}$ and greater than $12 \mathrm{~km}$ respectively. The other $17.2 \%$ of the respondents answered that they travel using the light rail service for $3 \mathrm{~km}-5 \mathrm{~km}$ and the small percentage compared to others $(14.7 \%)$ were respondents who travel for $1 \mathrm{~km}-3 \mathrm{~km}$ in their daily journey with AA-LRT service. Mostly these people travel almost more than $5 \mathrm{~km}$ per day on average. From this it is understood that passengers are very well know the service given by AA-LRT and whatever the result from the respondents is could be considered as reliable to the study.

\subsection{Expectations and Perceived Performance Analysis}

In this research the modified SERVQUAL model is used to assess passengers' expectations and perceptions regarding service quality in Addis Ababa light rail transit. Both expectations and perceptions were measured using a 7- point likert scale to rate their level of agreement or disagreement (1-strongly disagree and 7- strongly agree), on which the higher numbers indicate higher level of expectation or perceptions. Perceptions are based on the actual service they receive from Addis Ababa light rail transit while expectations are based on past experiences 
and information from friends. Table 4.5 below presents the mean score on each attributes of both perceptions and expectations.

Table-4.5 Mean scores of Expectations and Perceived Performance

\begin{tabular}{|c|c|c|c|}
\hline 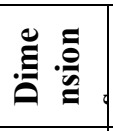 & $\begin{array}{c}\text { Evaluation Statements } \\
\text { (Attributes) }\end{array}$ & $\begin{array}{l}\text { Expectations } \\
\text { Mean score }\end{array}$ & $\begin{array}{c}\text { Perceived } \\
\text { performance } \\
\text { Mean score } \\
\end{array}$ \\
\hline \multirow{5}{*}{ 营 } & AA-LRT has up-to-date equipments. & 6.52 & 5.30 \\
\hline & Inside environment of the trains is clean and hygienic. & 6.49 & 5.65 \\
\hline & Shelters and seats at stations are available and well kept. & 6.73 & 4.65 \\
\hline & The physical environment of the stations is clean. & 6.50 & 5.68 \\
\hline & AA-LRT's employees are well dressed and appear neat. & 6.48 & 5.71 \\
\hline \multicolumn{2}{|c|}{ Average mean scores of tangibility } & 6.54 & 5.40 \\
\hline \multirow{5}{*}{ 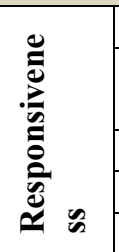 } & AA-LRT's employees are always willing to help customers. & 6.37 & 5.15 \\
\hline & $\begin{array}{l}\text { Employees tell customers exactly when services will be } \\
\text { performed. }\end{array}$ & 6.52 & 5.16 \\
\hline & Employees give prompt service to customers. & 6.49 & 5.25 \\
\hline & Employees are never too busy to respond to customers' request. & 6.40 & 5.46 \\
\hline & Customers can buy tickets without delay. & 6.55 & 5.01 \\
\hline \multicolumn{2}{|c|}{ Average mean score of responsiveness } & 6.47 & 5.21 \\
\hline \multirow{7}{*}{ 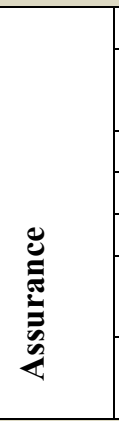 } & Customers are being informed if there are delays. & 6.66 & 4.45 \\
\hline & $\begin{array}{l}\text { AA-LRT takes immediate measure if failure occurs during } \\
\text { journey. }\end{array}$ & 6.63 & 4.43 \\
\hline & Employees are consistently courteous with customers. & 6.69 & 5.18 \\
\hline & AA-LRT maintain personal safety at stations. & 6.72 & 4.49 \\
\hline & AA-LRT maintain personal safety on train. & 6.73 & 4.63 \\
\hline & $\begin{array}{l}\text { The behavior of employees in AA-LRT instills confidence in } \\
\text { customers. }\end{array}$ & 6.62 & 5.15 \\
\hline & $\begin{array}{l}\text { Employees of AA-LRT have the knowledge to answer } \\
\text { customers' questions. }\end{array}$ & 6.53 & 5.55 \\
\hline \multicolumn{2}{|r|}{ Average of mean score of assurance } & 6.65 & 4.84 \\
\hline \multirow{6}{*}{ 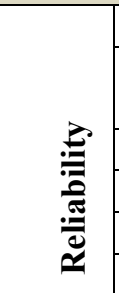 } & AA-LRT provides the service at the time it promised to do so. & 6.74 & 4.56 \\
\hline & $\begin{array}{l}\text { AA-LRT gives frequent and punctual service so that waiting } \\
\text { time is short. }\end{array}$ & 6.77 & 4.53 \\
\hline & AA-LRT keeps its records accurately. & 6.65 & 5.20 \\
\hline & AA-LRT performs the service right the first time. & 6.70 & 4.53 \\
\hline & Announcements on the train are clear and understandable. & 6.65 & 5.68 \\
\hline & AA-LRT has dependable complaint handling system. & 6.74 & 4.65 \\
\hline \multicolumn{2}{|c|}{ Average mean score of reliability } & 6.71 & 4.86 \\
\hline \multirow{5}{*}{ 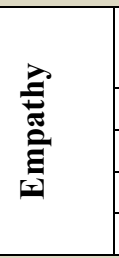 } & $\begin{array}{l}\text { AA-LRT gives attention to women, children, old and } \\
\text { handicapped. }\end{array}$ & 6.64 & 4.32 \\
\hline & AA-LRT's operating hours are convenient to all its customers. & 6.67 & 5.09 \\
\hline & AA-LRT has its customers' best interest at heart. & 6.67 & 5.17 \\
\hline & The employees understand the specific need of their customers. & 6.70 & 5.12 \\
\hline & AA-LRT provides affordable travel to all the sections of society. & 6.73 & 4.32 \\
\hline \multicolumn{2}{|r|}{ Average mean score of empathy } & 6.68 & 4.80 \\
\hline \multirow{5}{*}{ ن⿺辶ِّ } & Inside environment of the trains has comfortable temperature. & 6.74 & 4.54 \\
\hline & Seats are comfortable and well kept. & 6.70 & 4.63 \\
\hline & $\begin{array}{l}\text { There is no suffocation due to overcrowded or more stand } \\
\text { passengers. }\end{array}$ & 6.76 & 4.35 \\
\hline & Facilities inside the trains are in a good condition. & 6.71 & 4.46 \\
\hline & There is enough foot space with seats. & 6.58 & 5.19 \\
\hline \multicolumn{2}{|c|}{ Average mean score of comfort } & 6.70 & 4.64 \\
\hline
\end{tabular}

Source: own survey (2017) 
Compressed Table 4.5 above presents the results of expectations and perceptions mean scores for the mentioned six dimensions with each attributes. Regarding to expectation, among the dimensions reliability has got the highest average mean scores of 6.71 and considered as first, followed by comfort dimension which got average mean score of 6.70. This is basically indicates how important and crucial attributes under reliability and comfort are for maintaining the quality of service in AA-LRT to ensure customer satisfaction whenever passengers come across with this attributes almost all the respondents agree with the idea mentioned. The remaining four dimensions empathy, assurance, tangibility, responsiveness rank 3rd, 4th, 5th and 6th respectively. From the six dimensions responsiveness got less expectation score, this is mainly from the nature of the service that passengers are not as much contact with employees.

The perception rows of table 4.5 shows the actual service experience of the respondents. This is a real experience that the passengers have whenever they go from one place to another by using the service, even it can be compared to the other means of transportations. According to Reichhelid, (1996) perception is a psychological term related with an opinion about something viewed and assessed and it varies from customers to customers, as every customer has different beliefs towards certain services or products that play an important role in determining customer satisfaction. In many cases, customer perception is subjective, but it provides some useful insights for organizations to develop improvement strategies. Providing high level of quality service has become the selling point to attract customer's attention and is the most important driver that leads to satisfaction. The same thing is true for transportation service. It believed that passengers opinion regarding the service delivered to them reflect the current status of the service quality, what it should be and most important input for improvement by the service providers. In this regard tangibility scored the highest mean score of 5.40 and stand 1st as compared to the remaining five dimensions followed by responsiveness mean score of 5.21. The finding ranked reliability, assurance, empathy and comfort 3rd, 4th, 5th and 6th respectively. From the same table one can realize that the very least perception score given by the passengers is towards the comfort dimension which is warning AA-LRT to see itself from that way.

\subsection{Gap Size Analysis}

Perceived service quality scores are the difference between the perception and expectation scores (P-E) with a possible range of values from -6 to +6 ( -6 stands for very dissatisfied and +6 means very satisfied). The perceived service quality score measures the service gap or the degree to which expectations exceed perceptions. The more positive the P-E scores, the higher the level of service quality leading to a higher level of customer satisfaction. Satisfaction and service quality are both treated together as functions of a customer's perceptions and expectations. In most cases, when expectation and perception are equal, service quality is satisfactory. In this research, the researcher use the disconfirmation paradigm which is based on the discrepancy theories. According to this paradigm, customer's satisfaction judgment are the result of customer's perceptions of the difference between their perception of performance and their expectations. Positive disconfirmation leads to increased satisfaction while negative disconfirmation leads to decreased satisfaction.

\subsubsection{Tangibility Dimension of AA-LRT Service}

Table-4.6:1 Mean of Perceived Performance, Expectation and Gap Score on Tangibles of AA-LRT

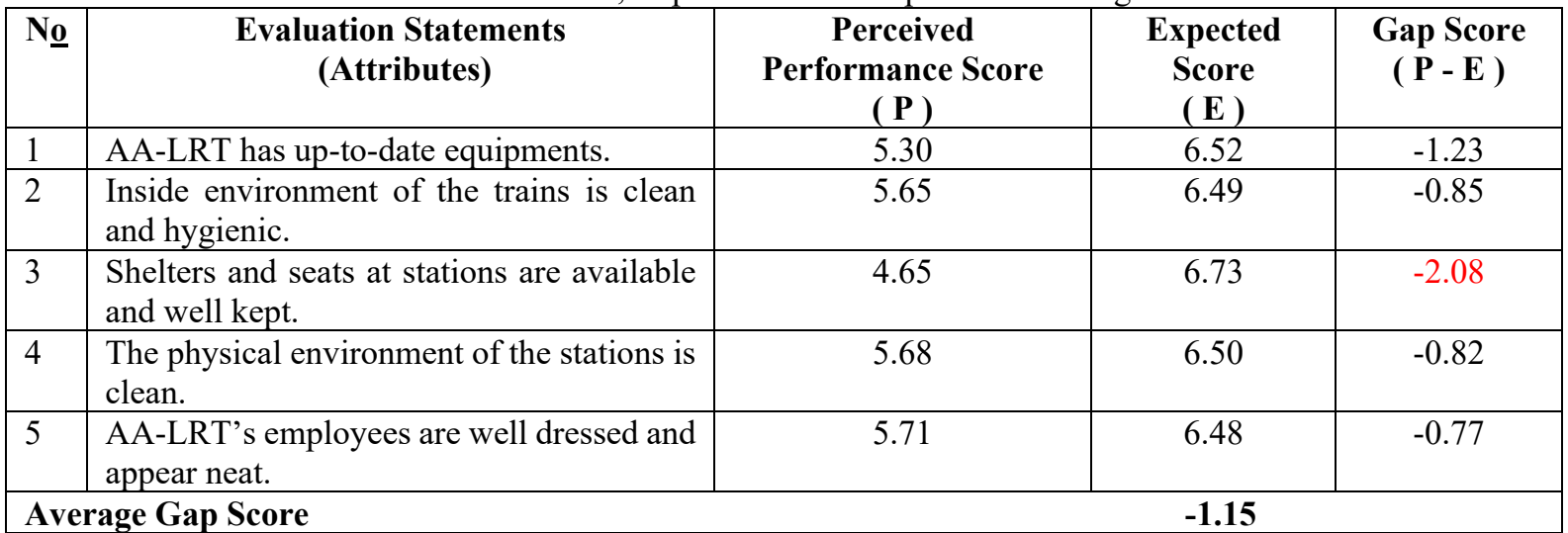

Source :own survey (2017),

As it can be seen from table 4.6.1, the gap score for P Tangibles 1-E Tangibles 1 is -1.23 , which implies that the perceived performance about the nature of modern looking equipment of the AA-LRT is less than the expectation of service commuters. The customers expect more from AA-LRT regarding its modern looking equipment. The gap score result of P Tangibility 2- E Tangibility 2, as can be seen from table 4.6.1 above, is -0.85 , which indicates that the mean score of customers' expectation exceeds the mean perceived performance score with regard to inside environment of the trains is clean and hygienic. The result shows that, the inside environment of AA-LRT trains were not clean and hygienic in the eyes of passengers. The gap was slightly low compared to the 
other attributes of tangibility dimension. However, customers are still in need with the service attribute as their perception mean was not matched with their expectations mean. The gap score between $\mathrm{P}$ Tangibility 3-E Tangibility 3 is -2.08 indicating that the score of mean expectation about shelter and seats at stations incredibly exceeds the score of mean perceived performance compared to other attributes of tangibility. This large negative gap between P Tangibility 3 and E Tangibility 3 shows that shelter and seats at stations were not available and well kept. From this one can say as AA-LRT need to give special attention to this attribute as the difference between passengers' expectation and perception was large in relative with other attributes of the same dimension. The gap score between $\mathrm{P}$ Tangibility 4 and E Tangibility 4 is -0.82 and it describes that to some extent, the physical environment of the stations were not clean and attractive at AA-LRT. The negative gap between P Tangibility 5 and E Tangibility 5 is 0.77 shows that employees are neither well-dressed nor neat in appearance. Generally, AALRT has scored a lower average gap score $(-1.15)$ in the tangibility dimensions in relation to other dimensions. This shows that the physical facilities and associated cleanness are somewhat good in the eyes of passengers except shelter and seats at stations which is account large gap and the AA-LRT is expected to maintain and/or improve it consistently.

4.6.2 Responsiveness Dimension of AA-LRT Service

Table-4.6.2: Mean of Perceived Performance, Expectation and Gap Score of Service Responsiveness of AA-LRT

\begin{tabular}{|l|l|c|c|c|}
\hline No & \multicolumn{1}{|c|}{\begin{tabular}{c}
\multicolumn{1}{|c|}{$\begin{array}{c}\text { Evaluation Statements } \\
\text { (Attributes) }\end{array}$} \\
\hline 1
\end{tabular}} & $\begin{array}{c}\text { Perceived Performance } \\
\text { Score } \\
\text { ( P ) }\end{array}$ & $\begin{array}{c}\text { Expected } \\
\text { Score } \\
\text { ( E ) }\end{array}$ & $\begin{array}{c}\text { Gap } \\
\text { Score } \\
\text { ( P - E ) }\end{array}$ \\
\hline 2 & $\begin{array}{l}\text { Employees tell customers exactly when services } \\
\text { will be performed. }\end{array}$ & 5.15 & 6.37 & -1.21 \\
\hline 3 & Employees give prompt service to customers. & 5.16 & 6.52 & -1.36 \\
\hline 4 & $\begin{array}{l}\text { Employees are never too busy to respond to } \\
\text { customers' request. }\end{array}$ & 5.25 & 6.49 & -1.24 \\
\hline 5 & Customers can buy tickets without delay. & 5.40 & -0.95 \\
\hline Average Gap Score & \multicolumn{2}{|c|}{6.55} & -1.54 \\
\hline
\end{tabular}

Source :own survey (2017)

The above table 4.6.2 indicates the data about the responsiveness. Responsiveness is the major dimension for service providers. However, this might roughly not true for transportation context as the customers not much contact with the operators. The gap between P Responsiveness 1 and E Responsiveness 1 is negative -1.21 . Accordingly, the mean of customers' expectation about the employee's willingness to help customers in their needs and desires (for example at waiting time, during journey, at ticket office). This negative implies that AA-LRT's employees are not willing to help passengers. The gap between P Responsiveness 2 and E Responsiveness 2 is negative -1.36. Accordingly, the mean of customers' expectation about the employee's willingness to tell customers the exact time when they provide service to the customers is greater than perceived performance. From this it can be concluded that AA-LRT's employees are not eager to inform the exact time when the service would be delivered to their customers. As indicated in table 4.5.2, there is a gap of -1.24 between the score of mean of $\mathrm{P}$ Responsiveness 3 and E Responsiveness 3. This means the customers' expectation about the employees' ability to provide quick service for their customers is greater than perceived performance. This gap (-1.24) implies that employees' of AA-LRT are not providing prompt service to their customers. On the other hand, the gap between customers' expectation and perceived performance (P Responsiveness 4- E Responsiveness 4) regarding to available time for employees in responding to customers request is negative $(-0.95)$. This implies that AA-LRT's employees are to some extent busy to responding to customers request. The gap here is somewhat not large compared to other attributes of the dimension, but the customers of AA-LRT still in need on time response to their request. P Responsiveness 5 - E Responsiveness 5, as presented in table 4.6.2, indicate negative gap (-1.54) about customer can buy ticket without delay (ticketing system) which implies that the customers are expecting more service from AA-LRT's. However, AA-LRT is not give attention to the ticketing system as customer were not able to buy it at the chosen time. In summary, AA-LRT score the average gap of $(-1.26)$ in responsiveness dimension which tells the company to improve it instantly. 
4.6.3 Assurance Dimension of AA-LRT Service

Table-4.6.3 Mean of Perceived Performance, Expectation and Gap Score of Service Assurance of AA-LRT

\begin{tabular}{|c|c|c|c|c|}
\hline No & $\begin{array}{c}\text { Evaluation Statements } \\
\text { (Attributes) }\end{array}$ & $\begin{array}{c}\text { Perceived Performance } \\
\text { Score ( P ) }\end{array}$ & $\begin{array}{l}\text { Expected Score } \\
\text { ( E ) }\end{array}$ & $\begin{array}{l}\text { Gap Score } \\
(\mathbf{P}-\mathbf{E})\end{array}$ \\
\hline 1 & $\begin{array}{l}\text { Customers are being informed if } \\
\text { there are delays. }\end{array}$ & 4.45 & 6.66 & -2.21 \\
\hline 2 & $\begin{array}{l}\text { AA-LRT takes immediate measure } \\
\text { if failure occurs during journey. }\end{array}$ & 4.43 & 6.63 & -2.20 \\
\hline 3 & $\begin{array}{l}\text { Employees are consistently } \\
\text { courteous with customers. }\end{array}$ & 5.18 & 6.69 & -1.50 \\
\hline 4 & $\begin{array}{l}\text { AA-LRT maintain personal safety at } \\
\text { stations. }\end{array}$ & 4.49 & 6.72 & -2.23 \\
\hline 5 & $\begin{array}{l}\text { AA-LRT maintain personal safety } \\
\text { on train. }\end{array}$ & 4.63 & 6.73 & -2.10 \\
\hline 6 & $\begin{array}{l}\text { The behavior of employees in AA- } \\
\text { LRT instills confidence in } \\
\text { customers. }\end{array}$ & 5.15 & 6.62 & -1.48 \\
\hline 7 & $\begin{array}{l}\text { Employees of AA-LRT have the } \\
\text { knowledge to answer customers' } \\
\text { questions. }\end{array}$ & 5.55 & 6.53 & -0.98 \\
\hline \multicolumn{3}{|c|}{ Average Gap Score } & \multicolumn{2}{|l|}{-1.81} \\
\hline
\end{tabular}

Source :own survey (2017)

This is important dimension in the railway context as it include the aspects of safety and security that are critical for passengers to feel confident in their passing through all service process in the transportation of AALRT and it measured with seven attributes to show if any gap seen in service quality delivered by AA-LRT. Thus, Table 4.6.3 shows the difference of the mean score between perceived performance and customers' expectation of ( P Assurance 1 and E Assurance 1) on customers will be informed if there are delays is -2.21 . The gap clearly shows that AA-LRT's employs ability in informing the delay information to customers is very low. Providing delay information (for example reason of delay and alternative solution) to the customers can help to rebuild their trust and increases their loyalty to the company service. Table 4.6.3again shows the gap between P Assurance 2 and E Assurance 2, which is -2.20 . This signify that AA-LRT not take immediate measure/solution while failure occurs during journey. When such issues encountered, customers need quick solution to the failure (problem). This will because it is about the time they have to reach their final place, without disturbing their program, schedule and work time. In this case, it can be inferred that passengers were not feel safe in their transactions because they are lacking trust in the transit service failure handling system. Concerning politeness of employees, there is a negative gap of (-1.50) which implies that employees are not consistently courteous to customers. The table also shows the gap between "P Assurance 4 and E Assurance 4" which result is -2.23 regarding to AA-LRT maintain personal safety at stations. Similarly, the gap between P assurance 5-E assurance 5 about personal safety on the train is resulted to -2.10 . Thetwo attributes are very important to passengers since they mostly seen with protection service, for example security in the trains to control theft and attack and underground stations which truthfully give confidence for passengers based on evidence from the gap result. The behavior of employees in AA-LRT instill confidence in customers shows negative result (-1.48) which indicated as $\mathrm{P}$ assurance 6-E assurance 6 . The gap result between (P assurance 7 and $\mathrm{E}$ assurance 7) about the knowledge of AA-LRT employees to answer the customers' questions properly is negative (-0.98). The gap was a little bit small compared to other attributes of the dimension, but the customers need more to be happy with the knowledge of employees to response to their request in AA-LRT service. 
4.6.4 Reliability Dimension of AA-LRT Service

Table-4.6.4: Mean of Perceived Performance, Expectation and Gap Score of Service Reliability of AA-LRT

\begin{tabular}{|l|l|c|c|c|}
\hline No & \multicolumn{1}{|c|}{$\begin{array}{c}\text { Evaluation Statements } \\
\text { (Attributes) }\end{array}$} & $\begin{array}{c}\text { Perceived Performance } \\
\text { Score (P) }\end{array}$ & $\begin{array}{c}\text { Expected Score } \\
\text { (E) }\end{array}$ & $\begin{array}{c}\text { Gap Score } \\
\text { ( P - E ) }\end{array}$ \\
\hline 1 & $\begin{array}{l}\text { AA-LRT provides the service at } \\
\text { the time it promised to do so. }\end{array}$ & 4.56 & 6.74 & -2.19 \\
\hline 2 & $\begin{array}{l}\text { AA-LRT gives frequent and } \\
\text { punctual service so that waiting } \\
\text { time is short. }\end{array}$ & 4.53 & 6.77 & -1.45 \\
\hline 3 & $\begin{array}{l}\text { AA-LRT keeps its records } \\
\text { accurately. }\end{array}$ & 5.20 & 6.65 & -2.17 \\
\hline 4 & $\begin{array}{l}\text { AA-LRT performs the service } \\
\text { right the first time. }\end{array}$ & 4.53 & 6.70 & -0.97 \\
\hline 5 & $\begin{array}{l}\text { Announcements on the train are } \\
\text { clear and understandable. }\end{array}$ & 5.68 & 6.65 & -2.09 \\
\hline 6 & $\begin{array}{l}\text { AA-LRT has dependable } \\
\text { complaint handling system. }\end{array}$ & 4.65 & 6.74 & $\mathbf{- 1 . 8 5}$ \\
\hline Average Gap Score
\end{tabular}

Source :own survey (2017)

According to Table -4.6.4, the mean difference between ' $\mathrm{P}$ ' Reliability 1-E Reliability 1 is -2.19 . This means, the mean score of customers' expectation about the AA-LRT's ability to honor its promises to do something in a certain time and its ability to perform it at the designated time is more than the mean of perceived performance score. As the gap is large and negative, one can understand that AA-LRT is not keeping its promise as expected by its customers. As indicated in Table 4.6.4 above, the mean difference between P Reliability 2 and E Reliability 2 is $(-2.24)$. This shows that there is a negative difference between the mean of customers' expectation regarding the capacity of AA-LRT's trains to give frequent and punctual service so that waiting time be short. This attribute is the central requirement in the rapid means of transportation which might be true for the light rail transit and main criteria that passengers look at. In this case, it is possible to conclude that frequency and punctuality of trains in AA-LRT were not in good quality based on the gap observed in light of respondents response. In addition to this, the perceived performance of AA-LRT's insistence on error free records is less by -1.45 from customer's expectation. This amount of gap implies that AA-LRT need to improve its issues of error free record. As per the same table here above, the mean of P Reliability 4 and E Reliability 4 have a gap score of -2.17 , which means that there is a gap between customer's expectation about the ability of AA-LRT to perform the service right the first time and perceived performance. Giving service right the first time directly related with the service level agreement. From this, one can observe that AA-LRT's performance to be right first time service is not matching the expectation of the customers. The table also shows that the difference between the mean score of customers' expectation and perceived performance (P Reliability 5 and E Reliability 5) concerning the ability of AA-LRT in providing clear and understandable announcements in the train is negative $(-0.97)$. The gap is somewhat small compared to others attribute of reliability dimension, but customers still expect more as mean result of their perceptions is less than the mean of their expectations. As per the respondents' response, there is -2.09 gap between their expectation and perceived performance regarding the ability of AA-LRT in AA-LRT not have dependable complaint handling system which indicated as E reliability 6-Preliability 6. It is believed that faithful complaint handling system is expected to solve problem encountered to customers in their daily contact, but the collected data is showing that there is high gap in complaint handling scheme in AA-LRT. This might be seen mostly with delay time, ticketing system and from drivers perceptive, not stopping trains at waiting stations. 
4.6.5 Empathy Dimension of AA-LRT Service

Table-4.6.5: Mean of Perceived Performance, Expectation and Gap Score on Empathy of AA-LRT

\begin{tabular}{|c|c|c|c|c|}
\hline No & $\begin{array}{c}\text { Evaluation Statements } \\
\text { (Attributes) }\end{array}$ & $\begin{array}{c}\text { Perceived Performance } \\
\text { Score (P) }\end{array}$ & $\begin{array}{c}\text { Expected } \\
\text { Score } \\
\text { (E) }\end{array}$ & $\begin{array}{c}\text { Gap } \\
\text { Score } \\
(\mathbf{P}-\mathbf{E})\end{array}$ \\
\hline 1 & $\begin{array}{l}\text { AA-LRT gives attention to women, children, } \\
\text { old and handicapped. }\end{array}$ & 4.32 & 6.64 & -2.33 \\
\hline 2 & $\begin{array}{l}\text { AA-LRT's operating hours are convenient to } \\
\text { all its customers. }\end{array}$ & 5.09 & 6.67 & -1.58 \\
\hline 3 & $\begin{array}{l}\text { AA-LRT has its customers' best interest at } \\
\text { heart. }\end{array}$ & 5.17 & 6.67 & -1.51 \\
\hline 4 & $\begin{array}{l}\text { The employees understand the specific need } \\
\text { of their customers. }\end{array}$ & 5.12 & 6.70 & -1.58 \\
\hline 5 & $\begin{array}{l}\text { AA-LRT provides affordable travel to all the } \\
\text { sections of society. }\end{array}$ & 4.32 & 6.73 & -2.42 \\
\hline \multicolumn{3}{|c|}{ Average Gap Score } & .88 & \\
\hline
\end{tabular}

Source :own survey (2017)

As illustrated in table 4.6.5 above, the gap score between P Empathy1 and E Empathyl is -2.33 which is incredible gap and implies that the AA-LRT is not giving sufficient individualized attention for its customers; pregnant women, children, old and handicapped. In this case, it can be concluded as the ability of AA-LRT in giving personal attention is therefore not satisfactory in the eyes of its customers. The gap score between $P$ Empathy 2 and E Empathy2 is -1.58 which implies that AA-LRT does not have convenient operating hours that fit to all customers. As a result, customers are not happy with the convenience and conduciveness of operating hours of AA-LRT. In the same manner, the gap score between P Empathy 3 and E Empathy 3 is -1.51, which implies that AA-LRT's employees have no best interest at heart for their customers. The gap of other empathy attribute, $\mathrm{P}$ Empathy 4- E Empathy 4, is -1.58 which indicates that the customer's expectation is greater than the actual performance regarding the AA-LRT employees understanding of the specific needs of customers. In the same table, the gap score between P Empathy 5 - E Empathy 5 is -2.42 , which is a large gap and implies that AA-LRT not provide affordable travel to all the sections of society. As per the respondents' response affordable travel which is mostly perceive with the price of the ticket that should consider the lower class society. This was the great mission of the light rail transit in Addis Ababa city. From this evidence, one can conclude that as affordability of travel in AA-LRT is not fitted with the expectations of customers.

4.6.6 Comfort Dimension of AA-LRT Service

Table-4.6.6: Mean of Perceived Performance, Expectation and Gap Score on Comfort of AA-LRT

\begin{tabular}{|c|c|c|c|c|}
\hline No & $\begin{array}{c}\text { Evaluation Statements } \\
\text { (Attributes) }\end{array}$ & $\begin{array}{c}\text { Perceived Performance } \\
\text { Score }(\mathbf{P})\end{array}$ & $\begin{array}{c}\text { Expected } \\
\text { Score } \\
\text { ( E ) }\end{array}$ & $\begin{array}{c}\text { Gap } \\
\text { Score } \\
(\mathbf{P}-\mathbf{E})\end{array}$ \\
\hline 1 & $\begin{array}{l}\text { Inside environment of the trains has } \\
\text { comfortable temperature. }\end{array}$ & 4.54 & 6.74 & -2.20 \\
\hline 2 & Seats are comfortable and well kept. & 4.63 & 6.70 & -2.07 \\
\hline 3 & $\begin{array}{l}\text { There is no suffocation due to overcrowded } \\
\text { or more stand passengers. }\end{array}$ & 4.35 & 6.76 & -2.41 \\
\hline 4 & $\begin{array}{l}\text { Facilities inside the trains are in a good } \\
\text { condition. }\end{array}$ & 4.46 & 6.71 & -2.25 \\
\hline 5 & There is enough foot space with seats. & 5.19 & 6.58 & -1.39 \\
\hline
\end{tabular}

Source :own survey (2017)

Comfort is one main reason why people prefer light rail transit. In this study, five measuring items are identified to passengers and the responses are analyzed and interpreted according to the values of the mean described in table 4.6.6 above. Accordingly, the mean difference between ' $\mathrm{P}$ ' comfort 1-E comfort 1 is -2.20 . This signify that the mean score of customers' expectation about comfortable temperature in the trains is more than the mean of perceived performance score. As the gap is big and negative, one can understand that AA-LRT is not keeping its trains inside environment with comfortable temperature as expected by its customers. This issue might be seen with ventilation service, air refresher and flexible windows were not considered by AA-LRT in the eyes of its customers. As indicated in Table 4.6.6 above, the mean difference between $\mathrm{P}$ comfort 2 and $\mathrm{E}$ comfort 2 is (2.07). This shows that there is a big difference between the mean of customers' expectation regarding comfortable seats and the mean of perceived performance. From this it is clear that seats on the train to some extent not 
comfortable and kept well. As per the same table here above, the mean of P Reliability 3 and E Reliability 3 have a gap score of -2.41 , which means that there is a incredible gap between customer's expectation about being free from suffocation due to overcrowded or more stand passengers in the trains and perceived performance. comfort is one of the criteria that typically considered by the customers next to affordability and speed, of these being free from suffocation is a good indicator. In this case, one can understand that AA-LRT' customers are not happy with regarding to overcrowding and/or more stand passengers in a single train as the mean of perceptions incredibly exceeds their expectations. As per the respondents' response, there is -2.25 gap between their expectation and perceived performance regarding the ability of AA-LRT in providing facilities inside trains in a good condition. This is big and negative gap implies that AA-LRT not provide facilities inside trains in a good condition as it expected by its customers. In addition to this, the perceived performance regarding to enough foot space with seating is less by -1.39 from customer's expectation. The mean gap result is fairly not big as compared to others attributes of comfort dimension. However, customers are still expect more from AA-LRT as the mean of their perceptions is less than the mean of their expectations. It is believed that modern trains are expected with comfortable seats and enough foot space that will create well being for the passengers at the time of journey, but the collected data is showing that there is a gap on enough foot space with seating in the trains of AA-LRT.

\subsection{Comparison of Service Quality Dimensions}

Table 4.7 Comparison of Service Quality Dimensions based on Average Gap Score

\begin{tabular}{|l|c|c|}
\hline \multicolumn{1}{|c|}{ Service Quality Dimensions } & Average Gap Score & Rank \\
\hline Tangibles & -1.15 & $6^{\text {th }}$ \\
\hline Responsiveness & -1.26 & $5^{\text {th }}$ \\
\hline Assurance & -1.81 & $4^{\text {th }}$ \\
\hline Reliability & -1.85 & $3^{\text {rd }}$ \\
\hline Empathy & -1.88 & $2^{\text {nd }}$ \\
\hline Comfort & -2.06 & $1^{\text {st }}$ \\
\hline
\end{tabular}

Source :own survey (2017)

The gap analysis is accurate in identifying service short falls in an operation (Parasuraman et al, 1994). This will help AA-LRT service operators and/or management to be familiar with which dimension/s need an improvement and in a considerable condition. The above table 4.7 present the rank of service quality dimension based on their size of gap score whereby the large gap ranked as first and least gap ranked last. Accordingly, the Larger mean gap score were identified for the dimensions of comfort quality which is ranked 1st with average gap score of (-2.06) followed by empathy took 2 nd rank with average gap score of (-1.88), reliability dimension average gap score (-1.85) and ranked 3rd, assurance dimension took rank 4th with average gap score of (-1.81) and comparatively, the least gap score were shown in the responsiveness dimension which is ranked 5th with average gap score of (-1.26) and the last rank 6 th taken by tangibility dimension with the least average gap score $(-1.15)$ in relative with other dimensions. This reflects that AA-LRT perform more on tangibility dimensions than other dimensions. On the whole, the result indicated that there is no service quality gap which shows positive result (difference between perception and expectation). This implies that there is no dimension on which passengers' perception is equal to or greater than their expectation for excellent AA-LRT service.

\subsection{Analysis for Overall Satisfaction Level}

In this study passengers satisfaction level was measured how much they have been satisfied with quality of service experienced in Addis Ababa light rail transit. It was measured using a seven-point likert scale in which (1- Highly dissatisfied and 7- Highly satisfied)

Table 4.8.1 Frequency of Respondents' Satisfaction Level

\begin{tabular}{|c|l|c|c|c|c|}
\hline \multicolumn{2}{|c|}{ Overall satisfaction level } \\
\hline \multirow{7}{*}{ Valid } & Frequency & Percent & Valid Percent & Cumulative Percent \\
\hline \multirow{5}{*}{} & Highly dissatisfied & 4 & 1.3 & 1.3 & 1.3 \\
\cline { 2 - 6 } & Dissatisfied & 15 & 4.7 & 4.7 & 5.9 \\
\cline { 2 - 6 } & Slightly dissatisfied & 39 & 12.2 & 12.2 & 18.1 \\
\cline { 2 - 6 } & Undecided & 59 & 18.4 & 18.4 & 36.6 \\
\cline { 2 - 6 } & Slightly satisfied & 151 & 47.2 & 47.2 & 83.8 \\
\cline { 2 - 6 } & Satisfied & 38 & 11.9 & 11.9 & 95.6 \\
\cline { 2 - 6 } & Highly satisfied & 14 & 4.4 & 4.4 & 100.0 \\
\cline { 2 - 6 } & Total & 320 & 100.0 & 100.0 & \\
\hline
\end{tabular}

Source: own survey (2017),SPSS out put 
Table 4.8.2 Descriptive Analysis of Respondents' Satisfaction Level

\begin{tabular}{|l|l|c|c|c|c|}
\hline \multicolumn{6}{|c|}{ Descriptive Statistics } \\
\hline & $\mathrm{N}$ & Minimum & Maximum & Mean & Std. Deviation \\
\hline Overall satisfaction & 320 & $\mathbf{1}$ & $\mathbf{7}$ & $\mathbf{4 . 5 9}$ & 1.192 \\
\hline Valid N (listwise) & 320 & & & & \\
\hline
\end{tabular}

Source: own survey (2017),SPSS out put

The frequency and respective percentage of responses of the question are shown on table 4.8.1 The overall satisfaction of the respondents indicates that only $4.4 \%$ were very satisfied and $11.9 \%$ were satisfied, $47.2 \%$ were slightly satisfied, $18.4 \%$ of the respondents were not able to decide their satisfaction level, $12.2 \%$ were slightly dissatisfied, $4.7 \%$ was dissatisfied and very insignificant number of the respondents (1.3) were highly dissatisfied. This show to the large hand that passengers were only slightly satisfied. From the response one can observe to one side the $18.2 \%$ of respondents who expressed their dissatisfaction, large number of respondents $47.2 \%$ have expressed that the level of their satisfaction is only slightly satisfied. This is validated by the service quality gaps that was revealed in the objective two whereby the respondent's perception did not match the expectation leading to negative satisfaction gap. This result warns AA-LRT need to improve its service more based on the gaps identified in each service quality measurements. As it shown in table 4.8.2above, the overall satisfaction level of respondents also analyzed by applying descriptive statistics and the result reveal that the mean score of the satisfaction 4.59 out of maximum of 7 indicates that there is a lot of extent for improving in the level of satisfaction.

\subsection{Correlation Analysis}

To answer the fourth basic research question and empirically examine the relationship between service quality dimensions and customer satisfaction in AA-LRT, non-parametric test (spearman's correlation) has been applied because it is appropriate method to measure the correlation when the data are measured at ordinal level (Andy, 2006).Moreover, the data in this study was collected on the bases of non-probability sampling methods and this also force us to use non-parametric test to be statistically valid. Correlations are the measure of the linear relationship between two variables. A correlation coefficient has a value ranging from -1 to 1 . Values that are closer to the absolute value of 1 indicate that there is a strong relationship between the variables being correlated whereas values closer to 0 indicates that there is little or no linear relationship (Fikre et al, 2009).According to Andy, (2006) the correlation coefficient is a commonly used measure of the size of an effect: Values of \pm 0.1 represent a small effect, \pm 0.3 is a medium effect and \pm 0.5 is a large effect. The sign of a correlation describes the type of relationship between the variables being correlated. A positive correlation coefficient indicates that there is a positive linear relationship between the variables and a negative value indicates a negative linear relationship between variables (Fikre et al, 2009).

Accordingly, Table 4.9 below presents the summary of correlation result between service quality dimensions and customer satisfaction.

Table 4.9 Spearman's rho correlation analysis result

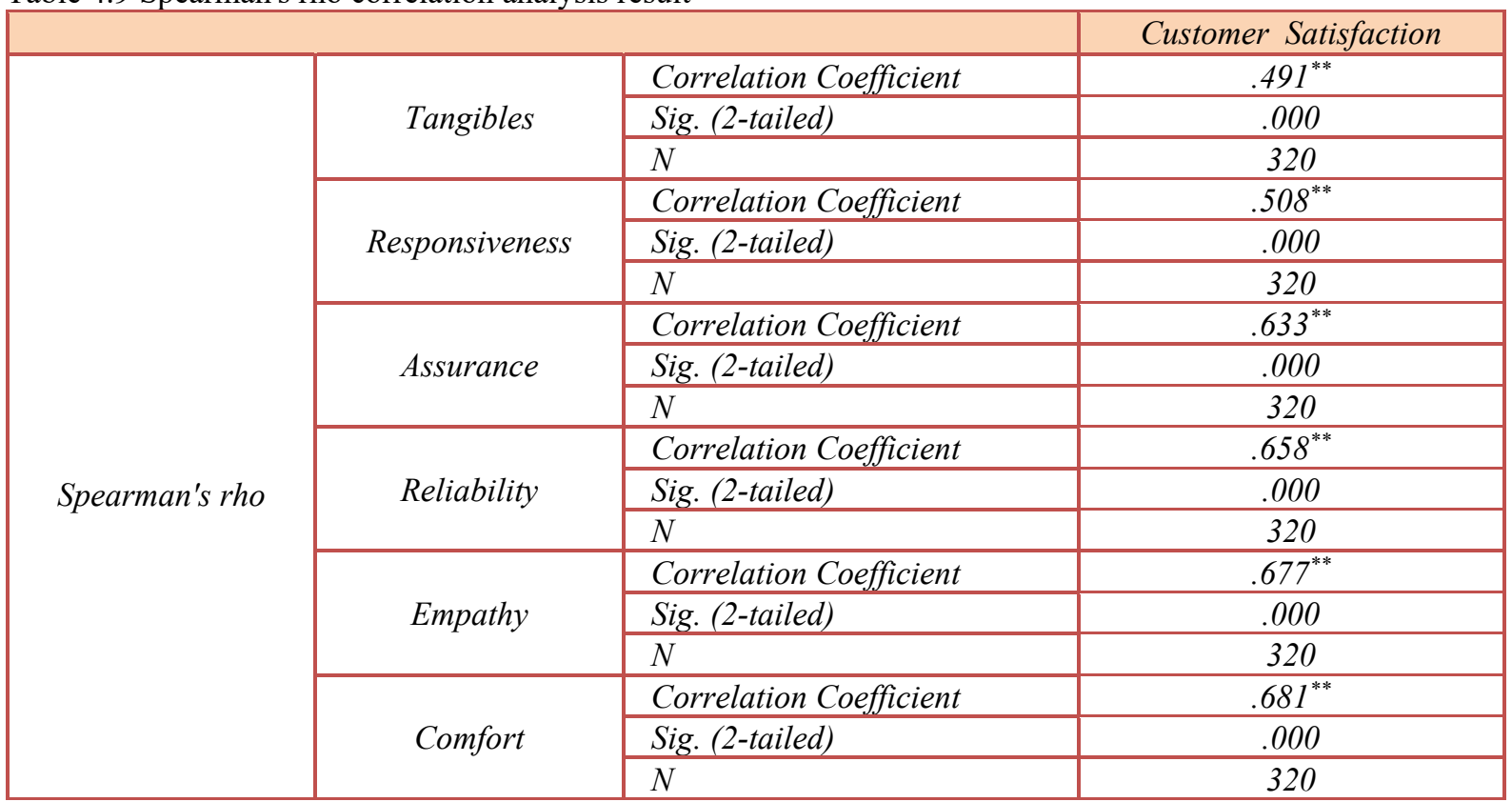

\footnotetext{
**. Correlation is significant at the 0.01 level (2-tailed).
} 


\subsubsection{Relationship between Tangibility and Customer Satisfaction}

From the beginning, tangibility dimension includes the physical facilities, equipment and appearance of employees of the organization. The results of correlation analysis reveal that tangibility is positively correlated with other service quality dimensions. The likely explanation of this factor is that customer often looks to any tangible indications which may be used as indicators of the service quality that customers use to evaluate the status of the service quality of an organization. From this perspective the study has investigated this issue and the result indicates that there is positive relationship between tangibility dimension and customer satisfaction. Having up to date equipment, keeping inside environment of the trains clean and hygienic, availability of shelter and seats at stations, clean and attractive stations and well dressed and neat employees significantly and positively correlated with customers' level of satisfaction.

\subsubsection{Relationship between Responsiveness and Customer Satisfaction}

The responsiveness dimension involves willingness to help customers and provide prompt services (Zeithaml et al., 1988). It is essential that employees are willing and able to help customers with prompt service and meet customers' expectation. As per the result shown in table 4.9 above there is positive relationship between responsiveness and customer satisfaction. This could have resulted from the passengers' perception on willingness of employees to help customers in AA-LRT service, telling customers exactly when services will be performed, giving prompt service to customers, Employees are never too busy to respond to customers' request, modern ticketing system so that passengers can buy without delay. This desire of customers is accepted and significantly and positively correlated with customers' level of satisfaction.

\subsubsection{Relationship between Assurance and Customer Satisfaction}

The assurance dimension refers to the knowledge and courtesy of employees and their ability to inspire trust and confidence including competence, courtesy, credibility and safety and security (Parasuraman et al., 1991). Mostly, this stems from the degree of confidence that the customer has in the service provider's staff. The result in table 4.9 indicates that there is positive relationship between assurance and customer satisfactions. Informing customers if there are delays, taking immediate measure if failure occurs during journey, consistently courteous of employees with customers, maintaining personal safety at stations, maintaining personal safety on train, the behavior of employees which instills confidence on the passengers, the employees knowledge to answer customers' questions have significant and positive relationship with customer satisfaction. Therefore, the service provider should strive to enhance further existing assurance status.

\subsubsection{Relationship between Reliability and Customer Satisfaction}

Reliability is the extent to which the service is delivered to the standards expected and promised. In essence, it represents the customer getting what they feel they have paid for. According to this study table 4.9 shows that, there is positive relationship between reliability and customer satisfaction. The attributes of reliability dimension expressed in this study like the ability of AA-LRT to provide the service at the time it promised to do so, the frequency and punctuality of trains so that waiting time to be short, ability of AA-LRT in keeping its record accurately, the ability of AA-LRT performs the service right the first time, clear and understandable announcements on the trains, having dependable complaint handling system. Hence, the study revealed that reliability attributes have positive and significant relationship with customer satisfaction.

\subsubsection{Relationship between Empathy and Customer Satisfaction}

Service customers often have expectations with regard to the extent to which the service provider appears to understand and be concerned about their individual needs and wants. The more the service provider can see things from the customer's point of view, the better it becomes. The core concept of empathy is to understand the needs of customers and provide individual attention. Employee/service provider and customer interactions are reflected through the empathy dimensions. As table 4.9shows, there is positive relationship between empathy and customer satisfaction. As a result, giving attention to individual customers, such as; giving attention to pregnant women, children, old and handicapped, convenience of AA-LRT operating hours, understanding of passengers' specific needs, having customers' best interest at heart, providing affordable travel to all the sections of society (for example considerable price of ticket) have positive relationship with customer satisfaction are confirms that empathy has positive relationship with customer satisfaction.

\subsubsection{Relationship between Comfort and Customer Satisfaction.}

As it mentioned in the literature review, additional dimension of comfort is very important to be included and considered to measure the service quality and customers satisfaction of railway services (Prasad \& Shekhar, 2010). Basically, comfort deals with several amenities, but mainly with the space available, or occupancy and conducive environment and/or wellbeing temperature. As the result of this study shows in table 4.9 above, there is large, positive and significant relationship between comfort and customer satisfaction. The positive association may be attributed to the fact that; keeping inside environment of the trains to comfortable temperature, enough, comfortable and well kept seats, avoiding suffocation due to overcrowded or more stand passengers, providing facilities inside the trains in a good condition (for example, tools for easy access of information) and presence of enough foot space with seats have positive and significant relationship with customer satisfaction. 


\section{Conclusion}

This research was mainly assessed the perceived service quality and level of passengers satisfaction with AA-LRT service from the perspective of passengers' expectations for excellent service quality and perceptions of the delivered service and clearly show the gap between passengers' expectations and perceived performances. It has observed that passengers perceive service quality as poor in all dimensions meaning their expectations fall short of what they experience in AA-LRT. In this regard, passengers were not the content with any dimension of service quality. All the dimensions show a gap between expected service and perceived service regardless of gaps size. Accordingly, predictable conclusions are generated from the findings of this study as fallow:-

$>$ On the whole, AA-LRT passengers had the highest expectations in reliability and comfort dimensions as well as highest perceptions in tangibility and responsiveness dimensions.

$>$ Looking at the findings, passengers had lowest mean score in responsiveness dimension in case of expectations as well as very lowest mean score in comfort and reliability dimensions in case of perceptions.

- The ability to deliver service as promised has a positive and significant relationship with customer satisfaction. However, the AA-LRT is not providing the service as promised, big problem with frequency and punctuality of trains and waiting time is so long. AA-LRT has no dependent complaint handling system whenever problem happened to its customers.

> The AA-LRT's physical facilities, equipments and the appearance of employees has significant and positive relationship with customer satisfaction. However, AA-LRT's service have negative gap in having modern looking equipment and physical facilities. Shelters against rain and sun as well seats at stations are not available as expected by customers. This is one of criteria that passengers use to evaluate service of AA-LRT as large gap is observed in this attribute.

- When the AA-LRT understand customer needs and provide individualized attention to their customer or increase the empathy they can also improve the level of customers satisfaction. However, the AA-LRT has a problem in giving individualized attention; not gives attention to handicapped, pregnant women, children and old, operating hours are not convenient to all its customers. AA-LRT has no employees who can have best interest at heart and understanding the specific need and the interest of the customers as expected.

$>$ Knowledge and competence of service providers and the ability to convey trust, confidence and safety have positive and significant relationship with customer satisfaction. However, AA-LRT service has large gap in informing passengers whenever there are delays, not give immediate solution wherever failure occurs during journey, not maintain personal safety both at stations and on the train, employees are not courteous as expected by customers.

- The space available, or occupancy and conducive environment and/or wellbeing temperature in the trains have positive and significant relationship with customer satisfaction. However, AA-LRT has a large gap in delivering quality service in this dimension. High suffocation problem due to passengers overload in a single train, not comfortable temperature and seats in the train, poor facilities conditions in the train and passengers are not happy even with foot space within a seats.

- As the AA-LRT's responsiveness became high the level of customer satisfaction also increases. Nevertheless, the AA-LRT is not telling the exact time when the service will be performed and not provide prompt service as expected by its customers. In addition to these employees of the AA-LRT are not always willing to help customers and to respond customers' question and very large gap in ticketing system in that passengers cannot buy it without delay and this can result reuse of a single ticket for a different travel time.

\subsection{Recommendation}

In light of findings and conclusion, the following practicable suggestions are given to AA-LRT in particular and ERC in general as a way forward in addressing its gaps observed in delivering quality service in all dimensions and eventually to achieve customer satisfaction that will lead the corporation in to profitability.

- AA-LRT should be providing the service as promised, frequency and punctuality of the trains should be managed and waiting time should be minimized. This can be achieved by regular headway or clearly scheduled time interval between trains operating in the same direction on a route. This also represents supposed waiting time for a passenger when he or she just missed a trip. Losing headway stability or regular passing of train at stations cause long waiting time. So that AA-LRT should focus on this issues. Increasing the number of train also another solution. AA-LRT should also establish trustworthy complaint handling system for its customers.

- AA-LRT should improve its physical facilities and equipments. Providing shelter and seats at stations as per customer expectation should be very important assignment for AA-LRT. Enough shelter and enough seating arrangement at stations can help AA-LRT to improve level of passengers satisfaction and create well managed environment at waiting time.

- Individualized attention should be given to passengers in order to better understand their needs and satisfy them. For example, special attention should be given to handicapped, old and pregnant women, this can be achieved even by functioning escalator service which is already made, specially at stations of high level. AA-LRT 
operating hours should be convenient to all its customers. Peak and off hour service should be differentiated and AA-LRT should focus to peak hour service since a large number of passengers at this time are civil servant. AA-LRT should have employees who can have best interest at heart and understanding the specific need and the interest of the passengers at all its service stage.

$>$ From the conclusion, passengers are never informed whenever there is a delay and they are kept at the station until so late before they are either informed that the train will be late or has broken down thus won't be able to depart. AA-LRT should be informing the passengers at the point of ticketing for them to make decisions whether to wait or find other means, this way, the passengers will feel valued and that AA-LRT has their best interest at heart and immediate solution should be taken at time of failure during journey. Regulations and standards of practice should be established to ensure safety and security of passengers. All the requirements and specifications should be outlined and awareness service should be provided.

- The finding also claim that high suffocation problem due to overload and more stand passengers in a single train. This is not only for suffocation problem, even it is not good for the service year of the train. There should be limitation or maximum number of passengers on a single train as per the standard, meaning allowing only the given standard number of passengers in a given single trip. AA-LRT should also be work on creating comfortable temperature and facilities conditions in the train (for example ventilation service, digital display service for passengers awareness and information while travelling and comfortable seats with enough foot space).

- AA-LRT should improve its responsiveness to increase level of customer satisfaction. There should prompt service and ticketing system should be improved. This is important issue specially at peak hours. Having sufficient employees at ticket office and/or establishing modern ticket system can be a solution. Reusing ticket is a common phenomenon with poor ticketing system through which AA-LRT loses money. Before rolling out the ticket, AA-LRT can use differentiated colored tickets for morning and evening to avoid the evening tickets being re-used in the morning than only for the two routes what AA-LRT have been practiced and deliver it promptly.

- In a general speaking, the Railway Corporation has a big responsibility in reducing overcrowding/congestion problem of this city (Addis Ababa) by improving quality of its service and integrates with other public transportations. The more the rail system services quality improved the more it can attract users of private vehicle which is a big reason of congestion in the city. There should be service quality standard that can be achieved. Highest RAILQUAL standards have to be set and gaps identified must be filled immediately. The corporation should periodically collect feedback from passengers in regard to service delivery and support such research which help to improve the service with latest information.

\section{References}

Agrawal, R. (2008). Public transportation and customer satisfaction, Global Business Review, 9(2), 257-272.

Barsky, J. D., \& Labagh, R. (1992).A strategy for customer satisfaction. The Cornell Hotel and Restaurant Administration Quarterly, 33(5), 32-40.

Bryman, A. \& Bell, E. (2003), Business research method, New York: Oxford University Press.

Cochran, W. G. 1963. Sampling techniques.

Fasil, T. (2014). Development of Service Quality Indicator for Ethiopian Freight Railways (Doctoral dissertation, AAU).

Habtamu, S. (2015). Pedestrian Level Crossing Safety on the East West Line of Addis Ababa Light Rail Transit (Doctoral dissertation, AAU).

Haileyesus, A. (2016). Assessment on Determinants of Passengers' Satisfaction: A Case Study on Addis Ababa Light Rail Transit Service (Doctoral dissertation, Addis Ababa University).

Hundal, B.S., (2015). Assessing the Service Quality of Northern Railway by using SERVQUAL Model.

Kefele, (2016). Assessment of the operation and stations facility of the light rail transit (Doctoral dissertation, AAU).

Marinov, M., Agajere, O.D., Bigotte, M., Proietti, D. and Gerenska, I., 2014. Customer satisfaction factors for light rail: what can we learn from a successful case? Transport Problems, 9(spec.), 45-59.

Oliver, R.L. (1999), “Whence consumer loyalty”, Journal of Marketing, 63(4), 33- 44.

Polit, D. F., \& Beck, C. T. (2004). Nursing research: Principles and methods. Lippincott Williams \& Wilkins.

Shukla, P. (2010). Effects of perceived sacrifice, quality, value, and satisfaction on behavioral intentions in the service environment. Services Marketing Quarterly, 31(4), 466-484.

Tebebu, T. (2014). Addis Ababa Light Rail Transit Signaling System Design Analysis (Doctoral dissertation, AAU). Tekle, A. (2014). Design Of Effective Railway Timetable Generation In Ethiopia (Doctoral dissertation, AAU). 